\title{
Obesity and the Food Environment Among Minority Groups
}

\author{
Angela M. Odoms-Young • Shannon N. Zenk • \\ Allison Karpyn • Guadalupe Xochitl Ayala • \\ Joel Gittelsohn
}

Published online: 19 July 2012

(C) Springer Science+Business Media, LLC 2012

\begin{abstract}
The prevalence of obesity is higher in racial/ethnic minority populations compared to non-Hispanic whites. Recently, a substantial body of literature has focused on understanding the role of the retail food environment in shaping racial, ethnic, and socioeconomic disparities in obesity risk. Compared to predominately white neighborhoods, retail food environments in minority neighborhoods have been found to be more "obesigenic" and offer fewer opportunities for healthy eating. Studies generally show that predominately African American and Native American neighborhoods have fewer chain supermarkets; more liquor/convenience stores; lower availability of healthy food options and lower-quality fresh
\end{abstract}

A. M. Odoms-Young ( $\square)$

Department of Kinesiology and Nutrition, College of Applied

Health Sciences, University of Illinois at Chicago,

1919 W. Taylor MC 517,

Chicago, IL 60612, USA

e-mail: odmyoung@uic.edu

S. N. Zenk

Department of Health Systems Science,

University of Illinois at Chicago College of Nursing,

845 South Damen Avenue, M/C 802,

Chicago, IL 60612, USA

A. Karpyn

The Food Trust, One Penn Center,

Suite 900, 1617 John F. Kennedy Blvd,

Philadelphia, PA 19103, USA

G. X. Ayala

Institute for Behavioral and Community Health,

San Diego State University,

9245 Sky Park Court, Suite 220,

San Diego, CA 92123, USA

J. Gittelsohn

Center for Human Nutrition,

Johns Hopkins Bloomerg School of Public Health,

615 N. Wolfe Street,

Baltimore, MD 21205, USA produce than predominately white neighborhoods. However, results from studies examining food environments in Hispanic/ Latino neighborhoods have been mixed. While several studies report an association between retail food environments, dietary intake, and obesity risk in children and adults, findings vary depending on the aspect of the food environment being studied, measures being used, target population considered, and geographic area where the study was conducted.

Keywords Obesity $\cdot$ Food environment $\cdot$ Minority groups

\section{Introduction}

Obesity is epidemic in the United States and has been associated with an increased risk of numerous adverse physical and psychological health outcomes. Prevalence rates of obesity are significantly higher in racial/ethnic minority groups compared to non-Hispanic whites. For example, in adults, rates of obesity (body mass index $[\mathrm{BMI}] \geq 30 \mathrm{~kg} / \mathrm{m}^{2}$ ) for non-Hispanic blacks (49.6\%) exceed those for all other racial and ethnic groups [1]. Data from the most recent National Health and Nutrition Examination Survey (2009-2010) indicate that $21.2 \%$ of Hispanic and $24.3 \%$ of non-Hispanic black children and adolescents (ages $2-19$ years) are obese ( $\geq 95$ th percentile) compared to $14.0 \%$ of non-Hispanic whites [2] In addition, results from other national and local surveys (e.g., the Pediatric Nutrition Surveillance System) show equally high rates of obesity in American Indian/Alaska Native and Native Hawaiian children and adults [3, 4•,5].

Although the causes of obesity disparities are clearly multifactorial, unhealthful dietary patterns are a major contributor [6]. The diets of racial/ethnic minority groups commonly fall short of those recommended for obesity prevention, as well as the prevention and management of conditions in which obesity is a major contributor (e.g., 
diabetes and cardiovascular disease) [7, 8]. Suboptimal intakes of fruits, vegetables, whole grains, and excess consumption of sugar-sweetened beverages and fast food are documented in most minority populations [9]. There is considerable agreement among experts that multilevel approaches to behavior change, and those that integrate a systems approach have the greatest potential to improve dietary intakes and reduce the high prevalence of obesity in minority populations [10]. Still, researchers have traditionally centered on identifying and intervening on psychosocial and behavioral contributors to dietary intake and weight status at the individual level [11-13].

In the last decade, a substantial body of literature has highlighted the important role of environmental context in shaping obesity risk [14-16]. Although a variety of contexts are of interest (e.g., home, school, child care). A major focus of this work has centered on examining relationships between retail food environments, including food availability (the types of food outlets and food options available), affordability (cost and pricing of healthy foods options), quality (freshness and appearance of foods), and health behaviors and health outcomes [14]. A growing body of evidence suggests that geographic distribution of food resources in the United States are greatly influenced by race and ethnicity $[17,18]$. Several studies have found that retail food environments in minority neighborhoods are more "obesigenic" (i.e., promote the overconsumption of calories) and offer fewer opportunities for healthy eating compared to those in predominately white neighborhoods $[18,19]$.

With a particular focus on understanding racial/ethnic disparities in obesity, this review provides an overview of the literature examining inequities in retail food environments by neighborhood racial/ethnic composition and linking retail food environments, dietary intake, and obesity risk in racial/ethnic minority populations in the United States. It concludes by offering recommendations for additional research and potential interventions to improve retail food environments and food access in minority communities. In contrast to previous reviews that focus mainly on African Americans and Hispanics/Latinos, the current discussion also considers research related to retail food environments in American Indians/Alaska Natives and Native Hawaiians communities [19, 20, 21•, 22•].

\section{Neighborhood Racial/Ethnic Composition and Geographic Distribution of Retail Food Outlets and Healthy Food Options}

\section{Retail Food Environments in African \\ American Neighborhoods}

Research examining associations between retail food environments and obesity in minority populations has largely focused on the role of retail food stores in shaping obesity risk and obesity-related behaviors, specifically dietary intake $[20,22 \bullet, 23 \bullet 24]$. With a few exceptions, studies generally show that predominately African American neighborhoods have fewer chain supermarkets; more liquor/convenience stores; lower availability of healthy food options (e.g., fruits and vegetables); and lower-quality fresh produce than predominately white, and in some cases, Hispanic/ Latino neighborhoods $[18,23 \bullet, 25,26,27 \bullet, 28 \bullet \bullet, 29,30 \bullet$, 31-34]. For example, in a national study examining racial/ ethnic and socioeconomic differences in food outlet availability across 28,000 zip codes, Powell et al. [35] found that the availability of chain supermarkets in African American neighborhoods was only $52 \%$ of that in white neighborhoods even after adjusting for neighborhood income, with less relative availability in urban areas. Similarly, Bodor et al. [36・• ] assessed availability of food outlets and healthy food options in neighborhoods in New Orleans between 2004 and 2005. African American neighborhoods had fewer supermarkets and lower aggregate availability of fresh fruits and vegetables compared to other neighborhoods.

While most research has depended on objective measures of retail food environments, studies examining racial differences in perceived retail food environments have noted similar results, with African Americans tending to be less satisfied with the availability and selection of healthy food options in their residential neighborhoods, compared to whites. For example, Zenk et al. [37] found that satisfaction with neighborhood availability of fruits and vegetables was lower in neighborhoods that had proportionately more African American versus white or Hispanic/Latino residents. Some studies also note that African Americans tend to travel further to make food purchases compared to their white counterparts, suggesting that African Americans may leave their neighborhoods to seek better shopping opportunities. [38].

Differences in the geographic location of fast-food and full-service restaurants in predominately African American compared to white neighborhoods have also been reported [18]. Most studies have found that neighborhoods with higher concentrations of African American compared to white residents have greater availability of fast-food restaurants compared to full-service restaurants, and potentially fewer choices for prepared food sources overall [25, 39].

The price of healthy food options also can play an important role in shoppers' purchasing decisions, especially among low-income consumers. The inverse relationship between obesity and socioeconomic status (SES) is well documented, with the highest rates of obesity occurring among population groups with the highest poverty rates and the least education [1, 40]. Research examining affordability of healthy food options between predominately African American and white neighborhoods has yielded mixed results [32, 41••, 42••, 43]. 
Many studies have focused specifically on examining price differences in fresh fruits and vegetables. Studies generally report limited differences in the prices of fruits and vegetables in neighborhoods with predominately African American residents compared to white residents [33]. Nevertheless, a number of studies have noted that fruits and vegetables offered in African American neighborhoods are generally of lower quality [29, 38]. Studies that report differences in fruit and vegetable pricing suggest that racial disparities in both food prices and quality may be attributed to store type, specifically more convenience and smaller stores in African American neighborhoods compared to more supermarkets in white neighborhoods $[42 \bullet \cdot]$.

Retail Food Environments in American Indian/Alaska Native and Native Hawaiian Neighborhoods

In contrast to research targeting African American populations, fewer studies focus on retail food environments in American Indian/Alaska Natives communities. Although access to food stores and food options (particularly traditional foods) can vary greatly across these communities, findings from existing studies indicate that American Indian/Alaska Natives generally have limited access to diverse food outlets and/or healthy foods, with fewer supermarkets and more gas stations and convenience stores on or near American Indian reservations [3, 44, 45••]. O'Connell et al. [45••] used a standardized checklist to assess the availability and cost of a market basket of food items consistent with the US Department of Agriculture (USDA) Thrifty Food Plan in American Indian communities in Washington State. Fifty stores were identified including 25 convenience stores, 16 grocery stores, and 9 supermarkets. Only $38 \%$ of the checklist items were available across all stores. In addition, foods from the dairy and sugars/sweets groups had the greatest availability, whereas fruits and vegetables had the least. Although cost of the most commonly available items were the lowest in supermarkets, $34 \%$ of the reservations did not have a supermarket, with the nearest off-reservation supermarket for most being 10 miles away. We only identified one study targeting Native Hawaiians; however, patterns in retail food availability appear to be similar to those in African American and American Indian/Alaska Native communities [4•].

\section{Retail Food Environments in Hispanic/Latino Neighborhoods}

Whereas research examining retail food environments in other racial/ethnic groups has been fairly consistent, findings examining disparities between Latino/Hispanic and white neighborhoods have been mixed. Many studies report a greater number of smaller stores in predominately
Hispanic neighborhoods compared to white or racially mixed neighborhoods; whereas other studies have reported no difference in supermarket and grocery store access [46-50]. In contrast to smaller stores in African American and Native American communities, some evidence suggests that smaller stores in Latino neighborhoods may actually stock a wide variety of healthier food options. Emond et al. [51••] examined differences in availability and affordability of healthy food items within supermarkets compared to Hispanic/Latino grocery stores or tiendas in South San Diego County. Although the tiendas were smaller than supermarkets, availability and quality of fresh produce and low-fat milk were similar. Still, compared to the supermarkets surveyed, availability of lean meats at tiendas was limited. Furthermore, while the price per unit (item or pound) for most fresh produce was lower in tiendas, the cost for skim milk was significantly higher. Two studies examining retail food environments in small cities (Central Falls, Rhode Island and East Central New York) found that fresh fruits and vegetables were more available in the Hispanic/Latino compared to predominately white or mixed-race neighborhoods, but the prices were generally higher [52, 53]. Similar to studies involving African Americans, authors attributed the higher prices of fresh produce items in Hispanic/Latino neighborhoods to the lack of largevolume retailers. Likewise, studies examining availability and affordability of a market basket of foods based on the USDA Thrifty Food Plan guidelines have also found limited differences in availability but higher prices that made the basket less affordable [54].

Studies have also noted differences in restaurant availability in predominately Hispanic/Latinos compared to white neighborhoods. Powell et al. [39] found significantly fewer restaurants available in predominantly Hispanic neighborhoods, which had $60.9 \%$ the number of available full-service restaurants and $55.8 \%$ the number of fast-food restaurants compared to non-Hispanic neighborhoods. However, information about the availability and cost of healthy options in restaurants in predominately Hispanic/Latino neighborhoods is limited [55].

\section{Relationships between Retail Food Environments and Dietary Intake}

Evidence suggests that supermarkets and larger food stores generally provide better availability, selection, quality, and lower prices compared to smaller stores [56]. Research has found an association between living in a neighborhood with or in close proximity to a supermarket and better dietary quality and higher fruit and vegetable intakes even after controlling for individual/family level characteristics [25, 57-59]. Some 
studies have also reported an association between availability of healthy food options at both supermarkets and smaller grocery stores (specifically fruit and vegetables) and individual consumption of those options [60]. For example, studying fruit and vegetable access in a predominately African American (53\%) sample in New Orleans, Bodor et al. [60] found that respondents who had a small food store within $100 \mathrm{~m}$ of their home had a significantly higher mean intake of vegetables and a marginally significant higher mean intake of fruits. In addition, vegetable availability at retail stores (as measured by shelf space) was also positively associated with reported vegetable intake.

These inconsistencies in study results may be related to differences in study design and methods. Most studies use objective measures of the retail food environment; however, residents' perceptions of their environment and neighborhood boundaries may also play a role in the types of food outlets used, as well as the foods purchased. Generally, studies have found an association between positive food environment perceptions and greater fruit and vegetable intake and lesser consumption of unhealthy items, such as fast food. In their study of African American women in Detroit, Zenk et al. [61] found that women with a more positive perceptions of the selection/quality, but not affordability, of fresh produce at the retail outlet where they shopped was positively associated with intake, independent of store type and location as well as age, per capita income, and years of education. In contrast, in a diverse sample of adults in Southeastern Pennsylvania, Lucan and Mitra [62] found that negative perceptions of the retail food environment (perceived difficulty finding fruits and vegetables, having to travel outside of one's neighborhood to get to a supermarket, and perceived poor grocery quality) were not significantly associated with fruit and vegetable consumption but directly associated with fast food consumption.

Much of the literature also has been cross-sectional. Recent longitudinal studies suggest that relationships between retail food environments and dietary intake may not persist over time. Using 15 years of longitudinal data from the CARDIA (Coronary Artery Risk Development in Young Adults) study, Boone-Heinonen et al. [63・•] studied supermarket proximity and dietary practices among 5,115 black and white young adults across four cities. These authors found that greater supermarket availability was generally unrelated to dietary quality and fruit and vegetable intake. But the same relationship was not observed for fruit intake.

In addition, evidence suggests that the impact of the retail food environment varies depending on the aspect of the food environment being studied (e.g., availability of retail food outlets vs. availability of healthy food options), measures being used (e.g., neighborhood density of food outlets vs. distance to the nearest food outlet), population being targeted (e.g., African American vs. Hispanic/Latino), and geographic area where the study is conducted (e.g., Southeast vs. Midwest) and that relationships between retail food environments and dietary intake may be more intense in minority compared to white populations. For instance, based on their analysis of data from the ARIC (Atherosclerosis Risk in Communities), Morland et al. [25] found that fruit and vegetable intake for African Americans increased by $32 \%$ for each additional supermarket in the census tract compared to an increase of only $11 \%$ for white Americans. Similarly, Zenk et al. [64] reported the strongest relationships between the retail food environment and fruit and vegetable intake in Latinos compared to whites. Presence of a neighborhood large grocery store was associated with greater fruit and vegetable intake while presence of a neighborhood convenience store was associated with lower fruit and vegetable intake among Latinos compared to African Americans.

Similar to neighborhood availability of and proximity to supermarkets, a number of studies have found a positive association between living in a neighborhood with or in close proximity to fast-food restaurants and lower dietary quality and higher fast-food consumption [62, 64, 65••]. However, studies examining the impact of full-service restaurants on dietary intake are limited.

The majority of research linking retail food environments and dietary intake has targeted adults; fewer studies have been conducted with children and adolescents. Similarly, studies focused on minority children have generated inconsistent results $[66,67 \bullet \bullet]$. For example, a recent study by Ding et al. [67••] on the influence of community food environment on dietary intake in a diverse sample of children and adolescents ages 12-18 years of age in Boston, San Diego, and Cincinnati found no association between food outlet proximity and fruit and vegetable intake and instead identified home food environments as key to improving dietary intake. Similarly, Edmonds et al. [68] found no correlation between neighborhood (census tract) grocery store availability of fruit, vegetable, and juice and consumption of these foods in African American boys ages 1114 years residing in Houston, Texas. However, intake of vegetables and juices was positively correlated with availability of these foods at neighborhood restaurants.

While food availability is an important aspect of retail food environments, fewer have focused on price. In contrast to studies examining availability which have yielded mixed results, most studies have found a positive association between food prices at stores and restaurants and dietary intake $[67 \bullet \bullet, 68-70,71 \bullet \bullet]$. Examining the impact of prices on dietary intakes in 5 th grade children, Sturm and Datar [72] found lower prices for vegetables and fruits significantly predicted higher intake of those foods; higher dairy prices predicted lower frequency of milk consumption; and higher meat prices predicted increased milk consumption. However, price effects were not found for fast- 
food or soft-drink consumption. Authors noted racial/ethnic differences in dietary behaviors (e.g., Hispanic children eat fruit and vegetables more frequently; Hispanic, black and Asian children drink milk less often; black and Hispanic children eat fast-food more often), yet small sample sizes prohibited them from detecting meaningful racial/ ethnic differences between subgroups. Evidence from nationally representative studies with adolescents has also shown that lower fruit and vegetable prices and higher fast-food prices are related to higher fruit and vegetable consumption. Using data from the 2002 wave of the 1997 National Longitudinal Survey of Youth, Powell et al. [69] examined the impact of price on fruit and vegetable consumption in a diverse sample of young adults ages 1823 years. Higher levels of fruit and vegetable consumption were associated with lower fruit and vegetable prices, with a $\$ 1$ increase in the price of fruits and vegetables being associated with a $32 \%$ reduction in weekly consumption. Although the study found that the association between prices and fruit and vegetable intake differed based on SES (with lower to middle SES participants being more price responsive compared to their higher SES counterparts), differences in the relationship by race/ethnicity were limited. Several studies have also noted a relationship between fast-food prices and fast-food consumption and reported that this relationship may vary by race and ethnicity. Relationships between fast-food prices and obesity in 5th and 8th graders were examined in a study using consumption data from the ECLS-K (Early Childhood Longitudinal Study, Kindergarten Class of 1998-99) [73]. Overall, a $10 \%$ increase in the price of fast food was associated with $5.7 \%$ lower frequency of weekly fastfood consumption. Estimations across ethnicities showed that the price of fast food was statistically significant for white children but not for African American or Hispanic children despite the fact that minority children consumed fast food more frequently. Also, data from the National Longitudinal Study of Adolescent Health (Add Health), a cohort study of 20,745 adolescents representative of the US school-based population, were used to conduct an economic analysis of community-level fast-food prices and individual-level fast-food intake [70]. Gordon-Larsen et al. [74••] found that increases in community-level prices of fast food and soda were associated with reductions in individual-level fast-food consumption. However, relationships between fast-food consumption and prices of fast food and soda varied by gender and race/ethnicity. This study found a stronger association between food prices and fast-food intake for males and relatively greater price sensitivity for sodas versus burgers. The strongest association was observed for black males, with a $20 \%$ increase in the price of soda associated with a decrease of 0.25 visits to a fast-food restaurant per week [72].

\section{Racial/Ethnic Disparities in Retail Food Outlets, Healthy Food Options, and Obesity Risk}

Several studies have reported a relationship between availability and type of retail food outlet and availability and affordability of healthy food options and obesity [56, 73, $74 \bullet \bullet, 75-78]$. Much of this work has shown that better neighborhood availability and/or proximity to a supermarket is linked with a lower risk of obesity, whereas an inverse association has been noted for convenience stores [77, 78]. Additionally, neighborhood availability of healthy food options (mostly fruits and vegetables) has also been associated with a lower risk of obesity, even after controlling for race/ethnicity and other individual demographic and social factors (e.g., SES, age, gender) [57]. In addition, availability of fast-food restaurants has been linked with an increased risk of obesity, with the relationship potentially being more robust in minority than white populations [63••].

The strongest evidence supporting the link between retail food environments and obesity risk in minority populations has been conducted with children and adolescents. A major focus of this work has been examining the impact of food outlets located within both residential and school environments. Powell et al. [79] found that increased residential availability of chain supermarkets was a statistically significant predictor of lower adolescent BMI and overweight in a diverse sample of adolescents. Conversely, greater availability of convenience stores was associated with higher BMI and overweight [35]. In this study, Powell et al. [79] found that the association between supermarket availability and weight was more robust for African American students compared to white or Hispanic students. Similarly, after adjusting for other factors, Langellier et al. [80] found that the overweight prevalence was 1.6 percentage points higher at majority-Latino schools that had at least one corner store within a half-mile than at majority-Latino schools that did not have a corner store within a half-mile. The association between corner stores and overweight prevalence varied significantly between majority-Latino schools and schools that were majority-white or that had no racial/ethnic majority. In this study the presence of fast-food restaurants within a half-mile of schools was not associated with overweight prevalence among students [80].

Similar to studies examining relationships between retail food environments and dietary intake, most research examining associations with obesity has been cross-sectional. However, a recent longitudinal analysis suggests that retail food environment may contribute to an increase in the incidence in obesity. Auchincloss et al. [81••] used data from the Multi-Ethnic Study of Atherosclerosis to examine the association between perceived retail food environments and incidence in obesity during the 5-year follow-up. Greater perceived availability of healthy food was associated with 
a lower incidence of obesity after adjusting for baseline BMI and individual characteristics. However, it is important to note that one third to one half of African American and Hispanic women were excluded due to baseline obesity and could not be included in the analysis.

\section{Conclusions}

Research examining the impact of retail food environments on dietary intake and obesity risk has grown extensively in the last decade. As discussed in this review, evidence suggests that access to food resources within the retail food environment is greatly influenced by race and ethnicity; and availability of certain types of food outlets and food options, food prices, and food quality may encourage purchasing and consumption of healthier food options and lower obesity risk. Similarly, though not covered in this review, intervention studies also provide support for the role of retail food environments in shaping dietary intake and obesity [82••]. Yet, while studies generally demonstrate a relationship between retail food environments, dietary intake, and obesity, inconsistencies in findings across studies underscore the complexity of these relationships and the need to gain an in-depth understanding of differences in these associations by race/ethnicity $[30 \bullet \cdot]$.

While current research suggests an association between retail food environments, dietary intake, and obesity overall, mechanisms underlying these relationships are poorly understood, particularly in high-risk populations. Most studies examining retail food environments are forced to make assumptions about where people shop, purchasing habits, and other motivators related to food purchasing preferences and consumption [83, 84]. More work needs to be conducted that examine how actual locations traveled and shopping behaviors influence the relationship between retail food environments and diet and weight status $[85 \bullet \bullet, 86 \bullet \bullet$. Likewise, future studies should consider how multiple individual and geographic characteristics such as race, ethnicity, and SES, age, urbanicity, and gender, contribute to these relationships. For example, weight status is significantly influenced by gender [1]. However, few retail food environment studies including minority populations focus on differences in effects by gender. In addition, Richardson et al. [86••] found that neighborhood race disparities were most pronounced in lowdensity urban (largely suburban) areas where high-poverty/ high-minority areas had lower availability of grocery/supermarkets, and conveniences stores, and greater availability of fast-food restaurants than low-poverty/low-minority areas. Nevertheless, few studies consider variability in retail food environment effects based on urbanicity [87]. Healthy food availability, affordability, and quality might be a proxy for other aspects of neighborhood deprivation, such as crime and low economic viability, which may also contribute to poor dietary intake and obesity risk [88].

Furthermore, researchers need to consider several issues related to study design and measurement in retail food environment research. Most of the literature is crosssectional and uses objective measures of retail food environments. Yet, some evidence suggests a poor association between food environments assessed using objective measures and those perceived by community residents [89]. Less is known about racial/ethnic differences in perceived food environments. Research in this area has also primarily limited definitions of retail food environments to supermarkets, grocery, convenience stores, and/or fast-food outlets when defining retail food environments. While a few recent studies have included additional outlets such as farmers' markets, mobile food vendors, Supplemental Nutrition Program for Women, Infants, and Children only stores, and supercenters, most have not examined these differences by race/ ethnicity $[90,91]$. Consideration of diverse outlets may be particularly important when considering low-income and rural populations. Broda et al. [91] found that low-income consumers tend to spend a greater share of their food budget at these low-cost outlets, such as supercenters, compared to other families. In a study in rural Texas, Sharkey et al. [92] found that among nontraditional food outlets and convenience food stores, the largest variety of fruits and vegetables were found at dollar stores. A similar study by the same authors found that in rural Latino areas, residents' access food from a variety of sources including flea markets and mobile vendors, both of which would have been missed in studies that include traditional definitions of stores and restaurant locations [93].

In addition, most studies only assess the availability of commonly consumed fruits and vegetables. Strong evidence suggests cultural food preferences play an important role in food purchasing and consumption. Yet, only one study focused specifically on assessing the availability of culturally specific fruits and vegetables [27•]. Lastly, because most studies are cross-sectional, it is difficult to understand how availability, affordability, and quality within retail food environments impact dietary intake and obesity overtime. Nevertheless, as one study noted, a major challenge in studying relationships between retail food environments and obesity incidence is the existing high prevalence of obesity in high-risk minority populations at baseline [79].

Two areas that also warrant greater attention in studies of retail food environments are food away from home and price. Americans are consuming an increasing number of meals away from home [94]. Although several studies have focused on fast food, additional studies examining the impact of restaurants (particularly full-service restaurants) are warranted. Fast-food consumption has been associated with higher total energy intake and higher intakes of fat, saturated fat, 
carbohydrates, sugar, and carbonated soft drinks, and lower intake of fruits and vegetables [94]. In addition, studies that examined racial/ethnic differences in the impact of price of food away from home specifically on dietary intake were limited. Yet, price considerations may be particularly important when examining racial/ethnic differences in retail food environments, given evidence that some racial/ethnic minority groups place greater value on lower-cost foods and largerportion sizes when eating food away from home compared to whites. Moreover, a recent study using Nielsen data to examine the prices paid by consumers for goods at retail stores also suggests that certain racial/ethnic minority groups, specifically African Americans, may pay more for the same goods at retail stores than white households [91].

Although an increasing number of studies have examined relationships between retail food environments, dietary intake, and obesity, further research is needed. Few theories and frameworks focus specifically on understanding the mechanisms that underlie these relationships [95]. A more in-depth understanding of retail food environments and their contribution to obesity will provide a foundation for effective programmatic and policy approaches to decrease the disproportion of obesity burden in minority populations [96].

Disclosure No potential conflicts of interest relevant to this article were reported.

\section{References}

Papers of particular interest, published recently, have been highlighted as:

- Of importance

•- Of major importance

1. Flegal Km C, Margaret D, et al. Prevalence of obesity and trends in the distribution of body mass index among US adults, 1999-2010. JAMA. 2012;307(5):491-7.

2. Ogden CL, Carroll MD, et al. Prevalence of obesity and trends in body mass index among US children and adolescents, 1999-2010. JAMA. 2012;307(5):483-90.

3. Ahn MK, Juon HS, Gittelsohn J. Association of race/ethnicity, socioeconomic status, acculturation, and environmental factors with risk of overweight among adolescents in California, 2003. Prev Chron Dis. 2008;5(3):A75.

4. - Mau MK, et al. Environmental factors of obesity in communities with native Hawaiians. Hawaii Med J. 2008;67(9):233-6. Comparison of fast-food outlets and exercise resources across three communities with varying percentages of Native Hawaiians (NH) and to correlate these findings with obesity prevalence. Trends in obesity prevalence paralleled the percentage of NHs. Results confirm the increased frequency of obesogenic environmental factors and their correlation with obesity trends across three distinct NH communities. These results suggest that environmental factors may offer another means for reducing obesity disparities in minority communities.

5. Centers for Disease Control and Prevention. Obesity prevalence among low-income, preschool-aged children-United States, 19982008. MMWR Morb Mortal Wkly Rep. 2009;58(28):769-73.

6. Swinburn BA, et al. Diet, nutrition and the prevention of excess weight gain and obesity. Public Health Nutr. 2004;7(1A):123-46.

7. Piernas C, Popkin BM. Food portion patterns and trends among U.S. children and the relationship to total eating occasion size, 1977-2006. J Nutr. 2011;141(6):1159-64.

8. Casagrande SS, Wang Y, et al. Have Americans increased their fruit and vegetable intake? the trends between 1988 and 2002. Am J Prev Med. 2007 Apr;32(4):257-63.

9. Swinburn B. Obesity prevention in children and adolescents. Child Adolesc Psychiatr Clin N Am. 2009;18(1):209-23.

10. Adler NE, Stewart J. Reducing obesity: motivating action while not blaming the victim. Milbank Q. 2009;87(1):49-70.

11. McEligot AJ, et al. Diet, psychosocial factors related to diet and exercise, and cardiometabolic conditions in Southern Californian Native Hawaiians. Hawaii Med J. 2010;69(5 Suppl 2):16-20.

12. Boone-Heinonen J, Gordon-Larsen P, et al. Obesogenic clusters: multidimensional adolescent obesity-related behaviors in the U.S. Ann Behav Med. 2008;36(3):217-30.

13. Oude Luttikhuis H, Baur L, et al. Interventions for treating obesity in children. Cochrane Database Syst Rev. 2009 Jan 21;(1): CD001872.

14. Story M, et al. Creating healthy food and eating environments: policy and environmental approaches. Annu Rev Public Health. 2008;29:253-72.

15. Fitzgibbon M, Stolley MR. Environmental changes may be needed for prevention of overweight in minority children. Pediatr Ann. 2004 Jan;33(1):45-9.

16. Kumanyika SK. Environmental influences on childhood obesity: ethnic and cultural influences in context. Physiol Behav. 2008;94 (1):61-70.

17. Casagrande SS, Whitt-Glover MC, et al. Built environment and health behaviors among African Americans: a systematic review. Am J Prev Med. 2009;36(2):174-81.

18. Larson NI, Story MT, Nelson MC. Neighborhood environments: disparities in access to healthy foods in the U.S. Am J Prev Med. 2009;36(1):74-81.

19. Lovasi GS, et al. Built environments and obesity in disadvantaged populations. Epidemiol Rev. 2009;31(Journal Article):7-20.

20. Black JL, Macinko J. Neighborhoods and obesity. Nutr Rev. 2008;66(1):2-20.

21. Fleischhacker SE, et al. A systematic review of fast food access studies. Obes Rev. 2011;12(5):e460-71. Six databases were searched using terms relating to fast food. Only peer-reviewed studies published in English during a 10-year period, with data collection and analysis regarding fast-food access, were included. Forty articles met the criteria. Nearly half of the studies used their own set of features to define fast food. Studies predominantly examined the relationship between fast-food access and socioeconomic factors and $76 \%$ indicated fast-food restaurants were more prevalent in low-income areas compared with middle- to higherincome areas. Ten of 12 studies found fast-food restaurants were more prevalent in areas with higher concentrations of ethnic minority groups compared with Caucasians. Six adult studies found higher BMI was associated with living in areas with increased exposure to fast food; four studies, however, did not find associations. Further work is needed to understand if and how fast-food access impacts dietary intake and health outcomes; and if fast-food access has disparate socioeconomic, racelethnicity, and age associations.

22. - Giskes K, van Lenthe F, et al. A systematic review of environmental factors and obesogenic dietary intakes among adults: are 
we getting closer to understanding obesogenic environments? Obes Rev. 2011;12(5):e95-e106. This study examined whether physical, social, cultural, and economical environmental factors are associated with obesogenic dietary behaviors and overweight/ obesity among adults. Literature searches of databases identified studies examining environmental factors and the consumption of energy, fat, fiber, fruit, vegetables, sugar-sweetened drinks, meal patterns, and weight status. Twenty-eight studies were in-scope, the majority $(n=16)$ were conducted in the United States. Weight status was consistently associated with the food environment; greater accessibility to supermarkets or less access to takeaway outlets was associated with a lower BMI or prevalence of overweight/obesity. However, obesogenic dietary behaviors did not mirror these associations; mixed associations were found between the environment and obesogenic dietary behaviors. Living in a socioeconomically deprived area was the only environmental factor consistently associated with a number of obesogenic dietary behaviors. Associations between the environment and weight status are more consistent than that seen between the environment and dietary behaviors.

23. - Gustafson A, Hankins S, Jilcott S. Measures of the consumer food store environment: a systematic review of the evidence 2000 2011. J Community Health. 2011. Dec 10. A systematic review of primary, quantitative, observational studies, published in English that conducted an audit of the consumer food environment. The literature search included electronic, hand searches, and peerreviewed from 2000 to 2011. Fifty-six papers met the inclusion criteria. Six studies reported stores in low-income neighborhoods or high-minority neighborhoods had less availability of healthy food, while four studies found there was no difference in availability between neighborhoods. The results were also inconsistent for differences in food prices, dietary patterns, and weight status. This systematic review uncovered several key findings: 1) systematic measurement of determining availability of food within stores and store types is needed; 2) context is relevant for understanding the complexities of the consumer food environment; 3) interventions and longitudinal studies addressing purchasing habits, diet, and obesity outcomes are needed; and 4) influences of price and marketing that may be linked with why people purchase certain items.

24. Larson N, Story M. A review of environmental influences on food choices. Ann Behav Med Publ Soc Behav Med. 2009;38 Suppl 1 (Journal Article):S56-73.

25. Morland K, Wing S, Diez Roux A. The contextual effect of the local food environment on residents' diets: the atherosclerosis risk in communities study. Am J Public Health. 2002;92 (11):1761-7.

26. Morland K, Filomena S. Disparities in the availability of fruits and vegetables between racially segregated urban neighbourhoods. Public Health Nutr. 2007;10(12):1481-9.

27. - Grigsby-Toussaint DS, et al. Availability of commonly consumed and culturally specific fruits and vegetables in African-American and Latino neighborhoods. J Am Diet Assoc. 2010;110(5):746-52. The purpose of this study was to assess the availability of commonly consumed and culturally specific fruits and vegetables in retail food stores located in majority African American and Latino neighborhoods in southwest Chicago, Illinois. Stores located in neighborhoods in which the majority of residents were African American or Latino were more likely to carry fresh fruits and vegetables that were culturally relevant to the dominant group. Most stores, however, carried fewer than $50 \%$ of commonly consumed or culturally specific fruits and vegetables. Findings from this study highlight that limited availability of culturally specific as well as commonly consumed fruits and vegetables in the neighborhood may be a barrier to fruit and vegetable consumption among African Americans and Latinos.
28. •• Powell LM, Wada R, et al. Ethnic disparities in adolescent body mass index in the United States: the role of parental socioeconomic status and economic contextual factors. Soc Sci Med. 2012;75 (3):469-76. This paper examined the importance of household and economic contextual factors as determinants of ethnic disparities in adolescent BMI. Individual-level data from the National Longitudinal Survey of Youth 1997 for the years 1997-2000 were combined with economic contextual data on food prices, outlet density, and median household income. Ethnic differences in household demographic, parental SES, and economic contextual factors explained the majority of the male black-white (63\%), male Hispanic-white (78\%), and female Hispanic-white (62\%) BMI gaps but less than one half of the female black-white BMI gap (44\%). Adding the economic contextual factors increased the explained portion of the ethnic BMI gap for both female and male adolescents: the economic contextual factors explained $28 \%$ and $38 \%$ of the black-white and Hispanic-white BMI gaps for males and $13 \%$ and $8 \%$ of the black-white and Hispanic-white BMI gaps for females, respectively. Parental SES was more important in explaining the Hispanic-white BMI gap than the black-white BMI gap for both genders, whereas neighborhood economic contextual factors were more important in explaining the male BMI gap than the female BMI gap for both black-white and Hispanic-white ethnic disparities. A significantly large portion of the ethnic BMI gap, however, remained unexplained between black and white female adolescents.

29. Block D, Kouba J. A comparison of the availability and affordability of a market basket in two communities in the Chicago area. Public Health Nutr. 2006;9(7):837-45.

30. • Lee H. The role of local food availability in explaining obesity risk among young school-aged children. Soc Sci Med. 2012;74 (8):1193-203. This paper examines whether the lack of access to more healthy food retailers and/or the greater availability of "unhealthy" food purveyors in residential neighborhoods explains children's risk of excessive weight gain, and whether differential food availability explains obesity disparities. I do so by analyzing a national survey of US children followed over elementary school (ECLS-K) who are linked to detailed, longitudinal food availability measures from a comprehensive business establishment database (the National Establishment Time Series). Children who live in residentially poor and minority neighborhoods are indeed more likely to have greater access to fast-food outlets and convenience stores. However, these neighborhoods also have greater access to other food establishments that have not been linked to increased obesity risk, including large-scale grocery stores. When examined in a multilevel modeling framework, differential exposure to food outlets does not independently explain weight gain over time in this sample of elementary school-aged children. Variation in residential food outlet availability also does not explain socioeconomic and racial/ethnic differences. It may thus be important to reconsider whether food access is, in all settings, a salient factor in understanding obesity risk among young children.

31. Leone AF, et al. Store type and demographic influence on the availability and price of healthful foods, Leon County, Florida, 2008. Prev Chron Dis. 2011;8(6):A140.

32. Sturm R. Disparities in the food environment surrounding US middle and high schools. Public Health. 2008;122(7):681-90.

33. Zenk SN, et al. Fruit and vegetable access differs by community racial composition and socioeconomic position in Detroit, Michigan. Ethn Dis. 2006;16(1):275-80.

34. Baker EA, et al. The role of race and poverty in access to foods that enable individuals to adhere to dietary guidelines. Prev Chron Dis. 2006;3(3):A76.

35. Powell LM, Slater S, et al. Food store availability and neighborhood characteristics in the United States. Prev Med. 2007;44 (3):189-95. 
36. •- Bodor JN, et al. Disparities in food access: does aggregate availability of key foods from other stores offset the relative lack of supermarkets in African-American neighborhoods? Prev Med. 2010;51(1):63-7. This study examined in-store shelf space of key foods to test whether other types of stores might offset the relative lack of supermarkets in African American neighborhoods. New Orleans census tract data were combined with health department information on food stores open in 2004-2005. Shelf space of fruits, vegetables, and energy-dense snacks was assessed using a measuring wheel and established protocols in a sample of stores. Neighborhood availability of foods was calculated by summing shelf space in all stores within $2 \mathrm{~km}$ of tract centers. Regression analyses assessed associations between tract racial composition and aggregate food availability. African American neighborhoods had fewer supermarkets and the aggregate availability of fresh fruits and vegetables was lower than in other neighborhoods. There were no differences in snack food availability.

37. Zenk SN, et al. Multilevel correlates of satisfaction with neighborhood availability of fresh fruits and vegetables. Ann Behav Med. 2009;38(1):48-59.

38. Morland K, Filomena S. The utilization of local food environments by urban seniors. Prev Med. 2008;47(3):289-93.

39. Powell LM, Chaloupka FJ, Bao Y. The availability of fast-food and full-service restaurants in the United States: associations with neighborhood characteristics. Am J Prev Med. 2007;33(4 Suppl): S240-5.

40. Drewnowski A. Obesity, diets, and social inequalities. Nutr Rev. 2009;67 Suppl 1(Journal Article):S36-9.

41. • Ard J, Perumean-Chaney S, et al. Fruit and vegetable pricing by demographic factors in the Birmingham, Alabama, metropolitan area, 2004-2005. Prev Chronic Dis. 2010 Jul;7(4):A78. The purpose of the study was to determine whether neighborhood demographics were associated with prices of fruits and vegetables. Forty-four grocery stores in the Birmingham, Alabama, metropolitan area were surveyed to determine prices of 20 fruits and vegetables. Stores were geocoded and linked to the corresponding Census 2000 block group to obtain data for the independent variables: percentage African American, percentage with at least a high school diploma, and percentage of households below the poverty level. In the fall, there were no significant relationships between the predictors and prices of any fruits and vegetables in the survey. In the spring, the percentage who had at least a high school diploma was a predictor of price per serving for potatoes.

42. • Dunn RA, et al. Socio-economic status, racial composition and the affordability of fresh fruits and vegetables in neighborhoods of a large rural region in Texas. Nutr J. 2011;10:6. Data from the Brazos Valley Food Environment Project were used to identify all food stores in the rural region and the availability and lowest price of fresh whole fruit and vegetables in the food stores. The mean cost of meeting the USDA recommendation of fruit consumption from a high-variety basket of fruit types in our sample of stores was just over $\$ 27.50$ per week. Relying on the three most common fruits lowered the weekly expense to under $\$ 17.25$ per week, a reduction of $37.6 \%$. The effect of moving from a high-variety to a low-variety basket was much less when considering vegetable consumption: a $4.3 \%$ decline from $\$ 29.23$ to $\$ 27.97$ per week. Univariate regression analysis revealed that the cost of fresh produce was not associated with the racial/ethnic composition of the local community. However, multivariate regression showed that holding median income constant, stores in neighborhoods with higher percentages of black residents paid more for fresh fruits and vegetables. The proportion of Hispanic residents was not associated with cost in either the univariate or multivariate analysis.

43. Krukowski RA, et al. Neighborhood impact on healthy food availability and pricing in food stores. J Community Health. 2010;35 (3):315-20.
44. Gittelsohn J, Sharma S. Physical, consumer, and social aspects of measuring the food environment among diverse low-income populations. Am J Prev Med. 2009;36(4 Suppl):S161-5.

45. • O'Connell M, Buchwald DS, Duncan GE. Food access and cost in American Indian communities in Washington State. J Am Diet Assoc. 2011;111(9):1375-9. This study examined the number and type of food stores (convenience, grocery, supermarket) on federal reservations in Washington State, and the availability and cost of foods in the USDA Community Food Security Assessment Toolkit market basket, to describe the food environment of American Indians. Stores were identified by telephone survey of tribal headquarters, a commercial database, and on-site visitation. Foods were assessed using a standardized instrument containing 68 items in seven major food groups. Store type and availability and cost of foods were recorded on a checklist. Fifty stores were identified on 22 American Indian reservations, including 25 convenience, 16 grocery, and 9 supermarkets. Across all stores, about $38 \%$ of checklist items were available, with supermarkets having the most and convenience stores the fewest. Foods from the dairy and sugars/sweets groups were the most prevalent, while fresh fruits/ vegetables were the least. Cost of the most commonly available items was lowest in supermarkets. Seventeen reservations did not have a supermarket on their reservation, and the nearest offreservation supermarket was about 10 miles from the tribe's headquarters, which was used as the standard for distance calculations.

46. Galvez MP, et al. Race and food store availability in an inner-city neighbourhood. Public Health Nutr. 2008;11(6):624-31.

47. Powell LM, et al. Food store availability and neighborhood characteristics in the United States. Prev Med. 2007;44(3):189-95.

48. Moore LV, Diez Roux AV. Associations of neighborhood characteristics with the location and type of food stores. Am J Public Health. 2006;96(2):325-31.

49. Lisabeth LD, et al. The food environment in an urban Mexican American community. Health Place. 2010;16(3):598-605.

50. Hillier A, McLaughlin J, et al. The impact of WIC food package changes on access to healthful food in 2 low-income urban neighborhoods. J Nutr Educ Behav. 2012;44(3):210-6.

51. • Emond JA, Madanat HN, Ayala GX. Do Latino and non-Latino grocery stores differ in the availability and affordability of healthy food items in a low-income, metropolitan region? Public Health Nutr. 2012;15(2):360-9. A cross-sectional study conducted by three independent observers to audit 25 grocery stores identified as the main source of groceries for $80 \%$ of Latino families enrolled in a childhood obesity study. Stores were classified as supermarkets and tiendas on the basis of key characteristics. Tiendas were smaller than supermarkets. Availability of fresh produce did not differ by store type; quality differed for one fruit item. Price per unit (pound or piece) was lower in tiendas for most fresh produce. The cost of meeting the USDA's recommended weekly servings of produce based on an $2000 \mathrm{kcal} / \mathrm{d}$ diet was $\$ U S 3.00$ lower in tiendas compared with supermarkets $(P<$ 0.001). The cost of 1 gallon of skimmed milk was significantly higher in tiendas (\$US 3.29 vs. \$US 2.69; P=0.005) and lean (7\% fat) ground beef was available in only one tienda (10\%) compared with $10(67 \%)$ supermarkets $(P=0.01)$.

52. Sheldon M, et al. Availability, affordability, and accessibility of a healthful diet in a low-income community, Central Falls, Rhode Island, 2007-2008. Prev Chron Dis. 2010;7(2):A43.

53. Lopez-Class M, Hosler AS. Assessment of community food resources: a Latino neighborhood study in upstate New York. J Poverty. 2010;14(4):369-81.

54. Chaufan C, Davis M, Constantino S. The twin epidemics of poverty and diabetes: understanding diabetes disparities in a lowincome Latino and immigrant neighborhood. J Community Health. 2011;36(6):1032-43. 
55. Lee SH, Rowan MT, et al. Characteristics of prepared food sources in low-income neighborhoods of Baltimore City. Ecol Food Nutr. 2010;49(6):409-30.

56. Liese AD, Weis KE, et al. Food store types, availability, and cost of foods in a rural environment. J Am Diet Assoc. 2007;107(11):1916-23.

57. Moore LV, et al. Associations of the local food environment with diet quality - a comparison of assessments based on surveys and geographic information systems: the multi-ethnic study of atherosclerosis. Am J Epidemiol. 2008;167(8):917-24.

58. Morland K, Diez Roux AV, et al. Supermarkets, other food stores, and obesity: the atherosclerosis risk in communities study. Am J Prev Med. 2006;30(4):333-9.

59. Michimi A, Wimberly MC. Associations of supermarket accessibility with obesity and fruit and vegetable consumption in the conterminous United States. Int J Health Geogr. 2010;9:49.

60. Bodor J, Rose D, et al. Neighbourhood fruit and vegetable availability and consumption: the role of small food stores in an urban environment. Public Health Nutr. 2008;11(4):413-20.

61. Zenk S, Schulz AJ, et al. Multilevel correlates of satisfaction with neighborhood availability of fresh fruits and vegetables. Ann Behav Med. 2009;38(1):48-59.

62. Lucan SC, Mitra N. Perceptions of the food environment are associated with fast-food (not fruit-and-vegetable) consumption: findings from multi-level models. Int J Public Health. 2012;57 (3):599-608.

63. • Boone-Heinonen J, et al. Fast food restaurants and food stores: longitudinal associations with diet in young to middle-aged adults: the CARDIA study. Arch Intern Med. 2011;171(13):1162-70. Fifteen years of longitudinal data from the CARDIA study, a cohort of US young adults (aged 18-30 years at baseline) ( $n=$ 5115), with linked time-varying geographic information systemderived food resource measures. Using repeated measures from four examination periods ( $n=15,854$ person-examination observations) and conditional regression (conditioned on the individual), fast-food consumption, diet quality, and adherence to fruit and vegetable recommendations were modeled as a function of fastfood chain, supermarket, or grocery store availability (counts per population) within less than $1.00 \mathrm{~km}, 1.00-2.99 \mathrm{~km}, 3.00-4.99 \mathrm{~km}$, and 5.00-8.05 km of respondents' homes. Models were sexstratified, controlled for individual sociodemographic characteristics and neighborhood poverty, and tested for interaction by individual-level income. Fast-food consumption was related to fast-food availability among low-income respondents, particularly within 1.00-2.99 km of home among men (coefficient, 0.34; $95 \%$ CI, 0.16-0.51). Greater supermarket availability was generally unrelated to diet quality and fruit and vegetable intake, and relationships between grocery store availability and diet outcomes were mixed.

64. Zenk SN, et al. Neighborhood retail food environment and fruit and vegetable intake in a multiethnic urban population. Am J Health Promot Am J Health Promot. 2009;23(4):255-64.

65. • Hickson DA, et al. Associations of fast food restaurant availability with dietary intake and weight among African Americans in the Jackson Heart Study, 2000-2004. Am J Public Health. 2011;101 Suppl 1:S301-9. Investigated cross-sectional associations of fast-food restaurant availability (FFR) with dietary intake and BMI and waist circumference in 4740 African American Jackson Heart Study participants (55.2 12.6 years, $63.3 \%$ women). FFR availability was investigated using circular buffers with differing radii centered at each participant's geocoded residential location. We observed no consistent associations between FFR availability and BMI or waist circumference. Greater FFR availability was associated with higher energy intake among men and women younger than 55 years, even after adjusting for individual SES. For each standard deviation increase in 5-mile FFR availability, the energy intake increased by 138 kilocalories $(C I=$
$70.53,204.75)$ for men and 58 kilocalories $(C I=8.55,105.97)$ for women. We observed similar associations for the 2-mile FFR availability, especially in men. FFR availability was also unexpectedly positively associated with total fiber intake.

66. An R, Sturm R. School and residential neighborhood food environment and diet among California youth. Am J Prev Med. 2012;42(2):129-35.

67. •• Ding D, et al. Community food environment, home food environment, and fruit and vegetable intake of children and adolescents. J Nutr Educ Behav. 2011 Apr 28. A cross-sectional survey was conducted with re-administration to assess test-retest reliability. Adolescents, parents of adolescents, and parents of children $(n=458)$ were surveyed in San Diego, Boston, and Cincinnati. Most subscales had acceptable reliability. Fruit and vegetable (FV) intake was positively associated with availability of healthful food $(r=0.15-0.27), F V(r=0.22-0.34)$, and ratio of more-healthful/lesshealthful food in the home $(r=0.23-0.31)$ and was negatively associated with less-healthful food in the home $(r=-0.17$ to -0.18$)$. Home food environment was associated with household income but not with community food environment.

68. Edmonds J, et al. Ecological and socioeconomic correlates of fruit, juice, and vegetable consumption among African-American boys. Prev Med. 2001;32(6):476-81.

69. Powell LM, Zhao Z, Wang Y. Food prices and fruit and vegetable consumption among young American adults. Health Place. 2009;15(4):1064-70.

70. Powell LM, Han E, Chaloupka FJ. Economic contextual factors, food consumption, and obesity among U.S. adolescents. J Nutr. 2010;140(6):1175-80.

71. • Powell LM, Han E. The costs of food at home and away from home and consumption patterns among U.S. adolescents. J Adolesc Health Off Publ Soc Adolesc Med. 2011;48(1):20-6. Individual-level data on adolescents were drawn from the Child Development Supplement of the Panel Study of Income Dynamics combined at the zip code level with external economic contextual data. Multivariate regression analyses were used to estimate the associations between food consumption categories and the economic contextual factors. Fast-food and food-at-home prices were not significantly associated with any of the food consumption categories in the full sample. However, among poor adolescents, higher fast-food prices were associated with higher levels of nonmeat protein consumption. Food store outlet availability was found to have very small significant associations with some food consumption categories but no significant associations were found for restaurant outlets.

72. Sturm R, Datar A. Regional price differences and food consumption frequency among elementary school children. Public Health. 2011;125(3):136-41.

73. Sturm R, Datar A. Body mass index in elementary school children, metropolitan area food prices and food outlet density. Public Health. 2005;119(12):1059-68.

74. •• Gordon-Larsen P, Guilkey DK, Popkin BM. An economic analysis of community-level fast food prices and individual-level fast food intake: a longitudinal study. Health Place. 2011;17 (6):1235-41. Used nationally representative, longitudinal data to examine how community-level food price variation was associated with individual-level fast-food intake by race/ethnicity and income across waves II (1996) and III (2001-2002) of the National Longitudinal Study of Adolescent Health $(n=11,088)$ from 158 baseline and 363 follow-up US counties. Negative binomial regression models predicting the number of fast-food meals per week show strong relationships between fast-food consumption and prices of fast food and soda that varied by gender and racelethnicity. We found relatively stronger association between food prices and fastfood intake for males and relatively greater price sensitivity for soda versus burgers. In the group with strongest associations 
(black males), a $20 \%$ increase in the price of soda was associated with a decrease of 0.25 visits to a fast-food restaurant per week.

75. Zick CD, et al. Running to the store? the relationship between neighborhood environments and the risk of obesity. Soc Sci Med. (1982), 2009;69(10):1493-1500.

76. Rundle A, et al. Neighborhood food environment and walkability predict obesity in New York City. Environ Heal Perspect. 2009;117(3):442-7.

77. Howard PH, Fitzpatrick M, Fulfrost B. Proximity of food retailers to schools and rates of overweight ninth grade students: an ecological study in California. BMC Public Health. 2011;11(Journal Article): 68 .

78. Morland KB, Evenson KR. Obesity prevalence and the local food environment. Health Place. 2009;15(2):491-5.

79. Powell LM, Auld MC, et al. Associations between access to food stores and adolescent body mass index. Am J Prev Med. 2007;33(4 Suppl):S301-7.

80. Langellier BA, et al. The food environment and student weight status, Los Angeles County, 2008-2009. Prev Chron Dis. 2012;2(9):E61.

81. • Auchincloss AH, et al. Neighborhood health-promoting resources and obesity risk (the Multi-Ethnic Study of Atherosclerosis). Obes. 2012 Apr 19. This study hypothesized that environmental resources supporting walking and a healthy diet are associated with reduced obesity incidence. Data came from 4008 adults aged 45-84 years at baseline who participated in a neighborhood ancillary study of the Multi-Ethnic Study of Atherosclerosis. Participants were enrolled at six study sites at baseline (2000-2002) and neighborhood scales were derived from a supplementary survey that asked community residents to rate availability of healthy foods and walking environments for a 1-mile buffer area. Associations between incident obesity and neighborhood exposure were examined using proportional hazards and generalized linear regression. Among 4008 non-obese participants, 406 new obesity cases occurred during 5 years of follow-up. Neighborhood healthy food environment was associated with $10 \%$ lower obesity incidence per standard deviation increase neighborhood score. The association persisted after adjusting for baseline BMI and individual-level covariates and for correlated features of the walking environment but confidence intervals widened to include the null. Associations between neighborhood walking environment and lower obesity were weaker and did not persist after adjusting for correlated neighborhood healthy eating amenities.

82. •• Gittelsohn J, Rowan M. Preventing diabetes and obesity in American Indian communities: the potential of environmental interventions. Am J Clin Nutr. 2011;93(5):1179S-83S. Experiences and findings from three case studies of intervention trials in American Indian communities was examined including: the Pathways trial, which was a school-based trial that focused on children; the Apache Healthy Stores program, which was a food-store program that focused on food preparers and shoppers; and the Zhiwaapenewin Akino'maagewin trial, which was a multiinstitutional trial for First Nations adults that worked with food stores, elementary schools, and health and social services agencies. All three trials showed mixed success.

83. Beaulac J, Kristjansson E, Cummins S. A systematic review of food deserts, 1966-2007. Prev Chron Dis. 2009;6(3):A105.

84. Kerr J, et al. Predictors of trips to food desintations. Int J Behav Nutr Phys Act. 2012;9(1):58.

85. • Zenk S, Schulz AJ, et al. Activity space environment and dietary and physical activity behaviors: a pilot study. Health Place. 2011;17(5):1150-61. This study examined relationships among individual demographics, environmental features (e.g., fast-food outlet density, park land use) of residential neighborhoods and activity spaces, and weight-related behaviors (diet, physical activity). Participants' movement was tracked for 7 days using global positioning systems (GPS). Two activity space measures (one standard deviation ellipse, daily path area) were derived from the GPS data. Activity spaces were generally larger than residential neighborhoods; environmental features of residential neighborhoods and activity spaces were weakly associated; and some activity space environmental features were related to dietary behaviors. Activity spaces may provide new insights into environmental influences on obesity-related behaviors.

86. • Richardson AS, Boone-Heinonen J, et al. Are neighbourhood food resources distributed inequitably by income and race in the USA? epidemiological findings across the urban spectrum. BMJ Open. 2012;2(2):698. Using a national sample, the authors examined differences in neighborhood food resource availability according to neighborhood-level poverty and racial/ethnic population in non-urban, low-density urban, and high-density urban areas. Using neighborhood characteristics of participants in the National Longitudinal Study of Adolescent Health (Wave III, 2001-2002; $n=13995$ young adults aged 18-28 years representing 7588 US block groups), the authors examined associations between neighborhood poverty and racelethnicity with neighborhood food resource availability in urbanicity-stratified multivariable linear regression. Neighborhood race and income disparities were most pronounced in low-density urban areas, where highpoverty/high-minority areas had lower availability of grocery/ supermarkets and convenience stores and greater availability of fast-food restaurants than low-poverty/low-minority areas. However, in high-density urban areas, high-poverty/low-minority neighborhoods had comparatively greater availability of grocery/ supermarkets, convenience stores, and fast-food restaurants relative to low-poverty/low-minority areas.

87. Ford PB, Dzewaltowski DA. Neighborhood deprivation, supermarket availability, and BMI in low-income women: a multilevel analysis. J Community Health. 2011;36(5):785-96.

88. Williams LK, Thornton L, et al. Is the objective food environment associated with perceptions of the food environment? Public Health Nutr. 2012;15(2):291-8.

89. Jilcott SB, et al. Examining associations among obesity and per capita farmers' markets, grocery stores/supermarkets, and supercenters in US counties. J Am Diet Assoc. 2011;111(4):567-72.

90. Tester JM, Yen IH, Laraia B. Mobile food vending and the afterschool food environment. Am J Prev Med. 2010;38(1):70-3.

91. Broda C, Leibtag E, Weinstein DE. The role of prices in measuring the poor's living standards. J Econ Perspect. 2009;23(2):77-97.

92. Sharkey JR, Horel S, Dean WR. Neighborhood deprivation, vehicle ownership, and potential spatial access to a variety of fruits and vegetables in a large rural area in Texas. Int $\mathrm{J}$ Heal Geogr. 2010;9:26.

93. Sharkey JR, Dean WR, Johnson CM. Use of vendedores (mobile food vendors), pulgas (flea markets), and vecinos o amigos (neighbors or friends) as alternative sources of food for purchase among Mexican-origin households in Texas border colonias. J Acad Nutr Diet. 2012;112(5):705-10.

94. Kant AK, Graubard BI. Eating out in America, 1987-2000: trends and nutritional correlates. Prev Med. 2004;38(2):243-9.

95. Bodor JN, Rice JC, et al. The association between obesity and urban food environments. J Urban Health. 2010;87(5):771-81.

96. Rose D, et al. Neighborhood food environments and Body Mass Index: the importance of in-store contents. Am J Prev Med. 2009;37(3):214-9. 